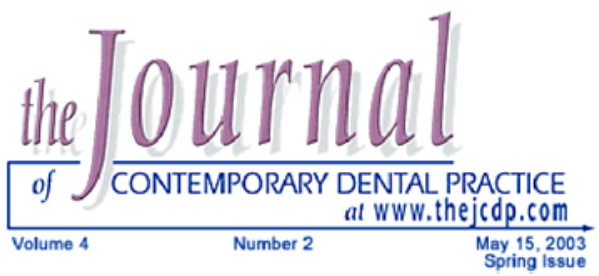

\title{
Common Errors on Panoramic Radiographs Taken in a Dental School
}

\section{Zühre Zafersoy Akarslan, BDS; Hülya Erten, BDS, PhD;}

Kahraman Güngör, BDS, PhD; llkkay Çelik, BDS

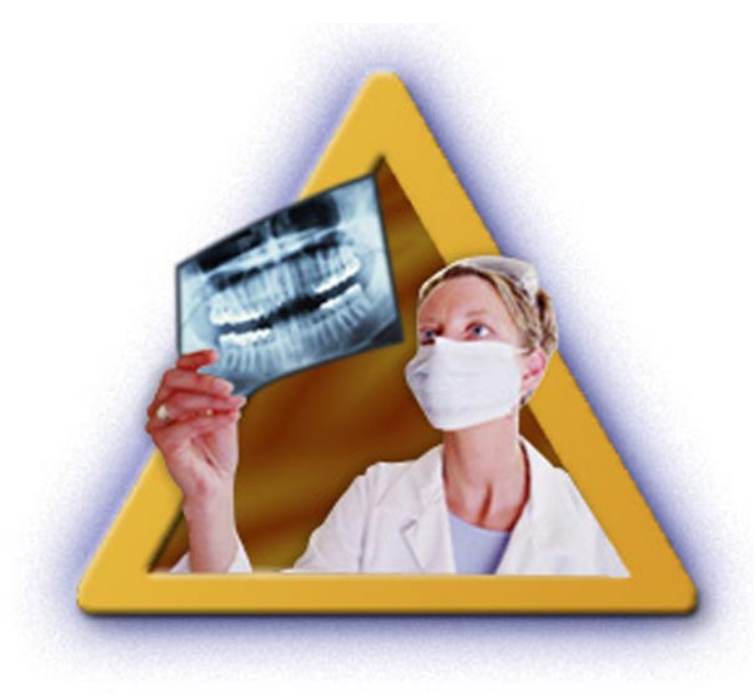

Abstract

The aim of this study is to evaluate the frequency of common errors seen on panoramic radiographs taken in the Radiology Department of a dental school by trained assistants. Four hundred and sixty radiographs were evaluated for 20 categories of common errors. Out of the evaluated radiographs, $37.61 \%$ were found to be error-free. The most common errors were found to be the palatoglossal airspace shadow of air above the tongue due to the patient not raising the tongue against the palate $(46.30 \%)$ and the superimposition of hyoid bone with the mandible $(26.30 \%)$ respectively. The least common error was found to be dirty or bent films $(0.21 \%)$. The quality of panoramic radiographs could be enhanced by improving radiographic technique.

Keywords: Panoramic radiography, errors, training, palatoglossal airspace

Citation: Akarslan ZZ, Erten H, Güngör K, et. al. Common Errors on Panoramic Radiographs Taken in a Dental School. J Contemp Dent Pract 2003 May;(4)2:024-034.

(c) Seer Publishing 


\section{Introduction}

Panoramic radiography is a radiographic technique for producing an image of the facial structures that includes both maxillary and mandibular arches and their supporting structures such as the maxillary antrum, nasal fossa, temporomandibular joint, styloid process, and hyoid bone on a single film. ${ }^{1}$ The image is obtained by rotation of the X-ray source and the film, at the same speed in the opposite direction around the head. ${ }^{2}$ In this technique, the X-ray beam passes through the jaws of from lingual to buccal and is directed at a slight upward angulation with respect to the occlusal plane.

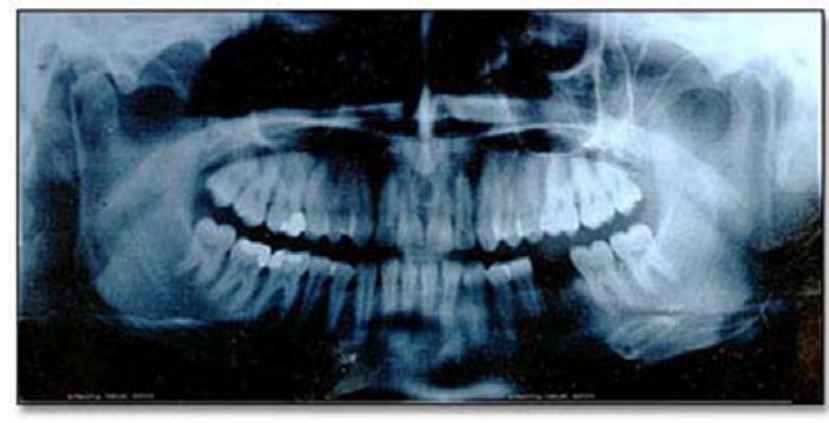

Panoramic radiography represents one of the major complementary examinations ${ }^{4}$; in recent years, there has been an increase in the use of it in dentistry. However, it coincides with an increased professional and public awarness of the risks associated with exposure to ionizing radiation. ${ }^{5}$ This risk puts pressure on the practitioner to maintain a high level of film quality in order to minimize the number of undiagnostical films.

In order to make a radiograph with a high diagnostic value, the operator must pay careful attention to patient positoning, film processing, and film handling procedures in general. Proper patient positioning requires the patient's back and spine to be erect with the neck extended, the Frankfurt plane parallel to the floor, and the dental arches and sagital plane positioned within the focal trough of the X-ray unit. ${ }^{1}$

Film processing could be done either manually or with automated film processors. For obtaining optimum quality, the processing procedure must be done carefully according to the manufacturer's recommendations.
Artifacts and common technical errors may cause radiographs to be of marginal or inadequate diagnostic quality ${ }^{6,7}$, leading to the possibility of compromised dental care. Several studies have been published on the frequency rate of errors seen on panoramic radiographs. Schiff et al. ${ }^{8}$ found that out of 1,000 panoramic radiographs, $79.7 \%$ had errors. On the other hand, Rushton et al. $^{9}$ reported that out of $1,813,99.2 \%$ had errors and Brezden et al. ${ }^{10}$ reported that of out of 500 evaluated radiographs, 499 had errors.

The aim of this study is to evaluate the frequency of common errors on panoramic radiographs taken in the Radiology Department of a dental school by trained assistants.

\section{Materials and Methods}

A total of 460 panoramic radiographs taken in the Radiology Department with an Orthopantomograph (OP100 Instrumentarium Corporation, Imaging Division, Finland) and developed in a roller transport automatic processor machine (Velopex, England) were evaluated by an experienced radiologist with 13 years experience. The radiographs were evaluated according to the following 20 categories of common errors modified from the Brezden et al. ${ }^{10}$ study:

1. Occlusal plane sloping downward due to chin tipped too low

2. Occlusal plane sloping upward due to chin raised too high

3. Overlap of the anterior teeth because of patient not biting on the bite-block

4. Asymmetrical placement of teeth due to the improper rotation of the head resulting in the improper placement of the patient's teeth in focal trough

5. Superimpostion of the spine on the condyles or rami caused by the patients biting the biteblock too far forward

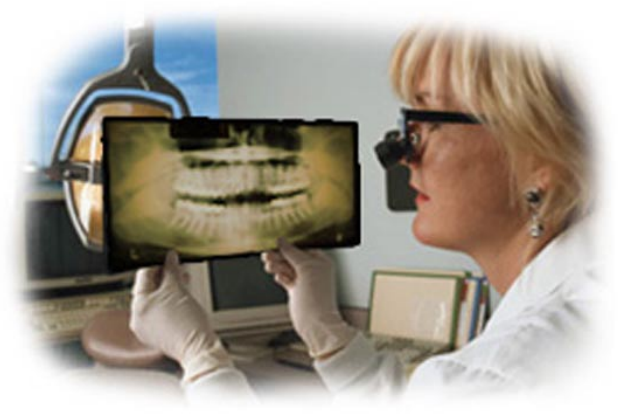


6. Radiopaque artifacts (earrings, necklace, prothesis, lead apron, spectacles, etc.)

7. Widening of anterior teeth due to the patient biting the bite-block too far back

8. Shadow above the tongue due to the patient not raising the tongue against the palate

9. Blurring of anterior teeth due to the patient biting the bite-block too far forward

10. Vertebral column causing extreme lightness in the anterior region as a result of the superimposed shadow of the spine

11. Superimposition of the hyoid bone with the body of the mandible according to the patient's Frankfurt plane not being parallel to the floor

12. Missing or doubled objects or abrubt shifting of image vertically due to the horizontal or vertical movement of the patient during exposure

13. Film fogged with a uniform gray shade caused by excessive length of processing time, developing solutions that are too warm, excessive storage time or temperature, contaminated and/or depleted chemicals, or improper darkroom lighting

14. Stains on film caused by accumulated chemicals and foreign material on the rollers of the automatic processor

15. Density too high due to processing errors or overexposure

16. Density too low due to processing errors or underexposure

17. Films dirty or bent

18. Marks on films (static electricity, fingerprints, emulsion tears, scratches)

19. Other errors (double exposure, pressure artifacts, film struck by light, film cut in half and taped together, foreign objects in casettes, lips open)

20. Narrowed anterior teeth due to patients biting the bite-block too far forward

The observer evaluated a series of panoramic radiographs having miscellaneous errors before evaluating the films in the study to ensure the judgment of errors was consistent. The radiologist evaluated radiographs taken in the Radiology Department through a nine month period under identical conditions in a dark room at the Radiology Department with a viewing box. Each radiograph was scored for the presence or absence of the 20 errors. Radiographs found to be inadequate were retaken after evaluation before they were given to the patients.

\section{Results}

From the evaluated 460 panoramic radiographs taken in the Radiology Department of a dental school in Turkey, 173 (37.61\%) were found to have no errors according to the 20 criteria.

The most common positioning error on the radiographs taken by trained asisstants was found to be a radiolucent area palatoglossal airspace over the roots of the maxillary teeth $(46.30 \%)$ due to the patient's tongue not being raised against the palate during exposure time. (Figure 1)

Superimpositon of the hyoid bone with the body of the mandible (26.30\%) and superimposition of the vertebral column on to the anterior teeth $(22.17 \%)$ were the next most common errors. (Figures 2 \& 3)

The least seen positioning errors were the widening of the anterior teeth due to the patient biting the bite-block too far back (1.30\%) and the vertical overlap of the anterior teeth due to the patient's not biting the bite-block, or not using a bite-block during the exposure $(2.39 \%)$.

On the evaluated radiographs, the most frequent technical errors were too high density (16.52\%) and too low density $(15.65 \%)$, respectively. (Figures 4 \& 5)

The least common error was found to be the presence of dirty or bent films (0.21\%). (Figure 6)

Some of the films had more than one error so the total percentage exceeds $100 \%$. The frequency of occurance of the most common errors is presented in Table 1.

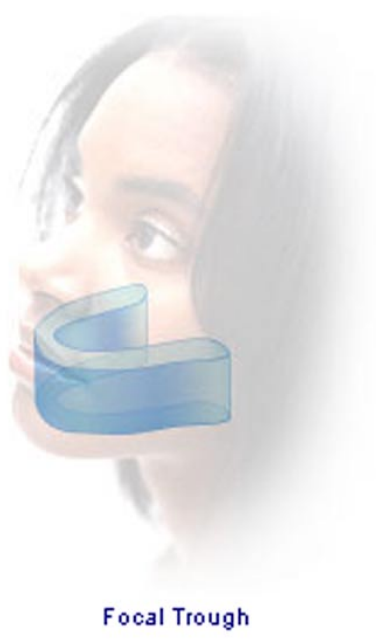




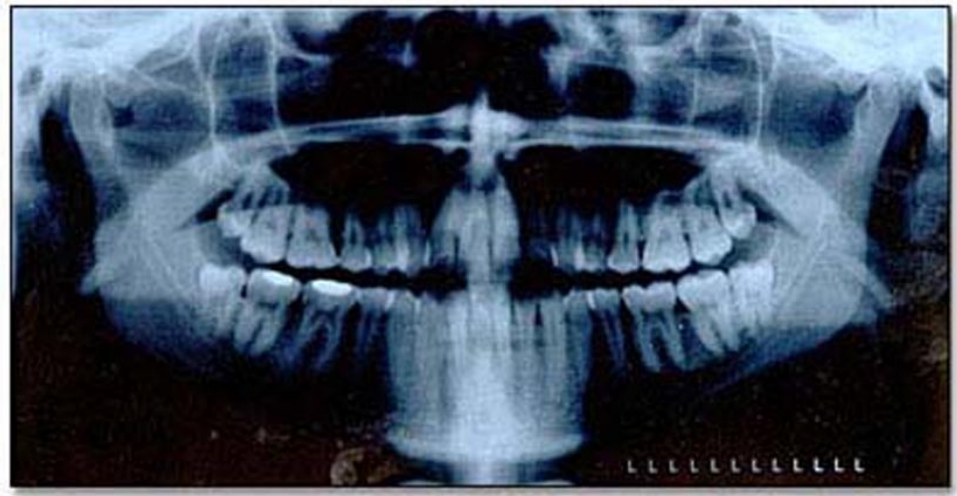

Figure 1. Palatoglossal airspace over the roots of the maxillany teeth.

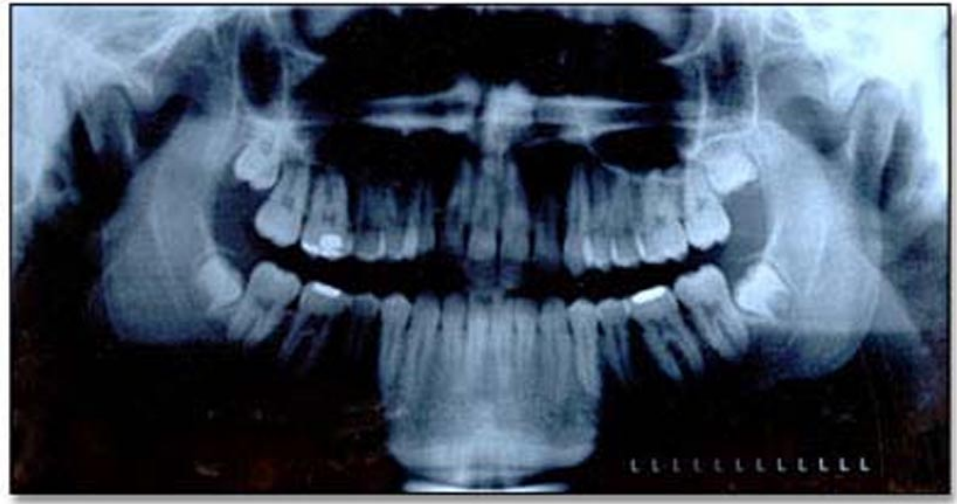

Figure 3 . Vertebral column superimposed over the anterior teeth.

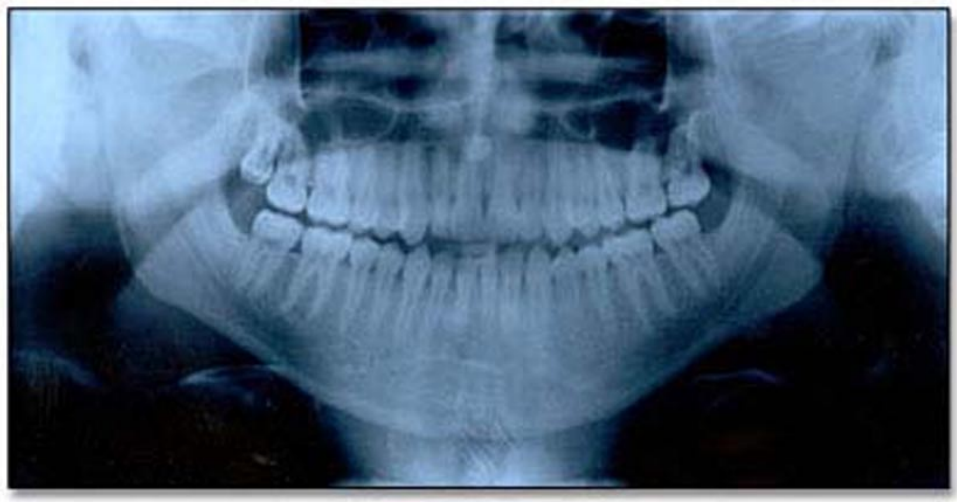

Figure 5. Film density too low.

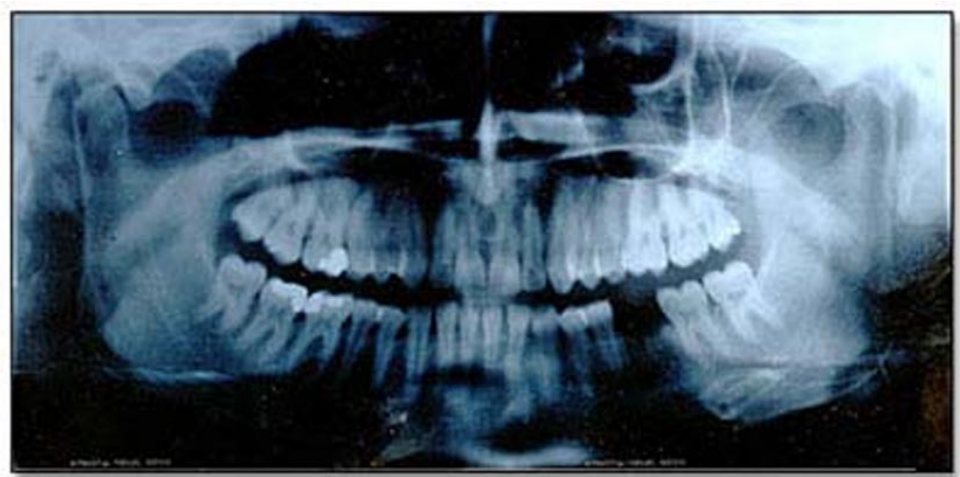

Figure 2. Superimposition of the hyoid bone on the body of the mandible.

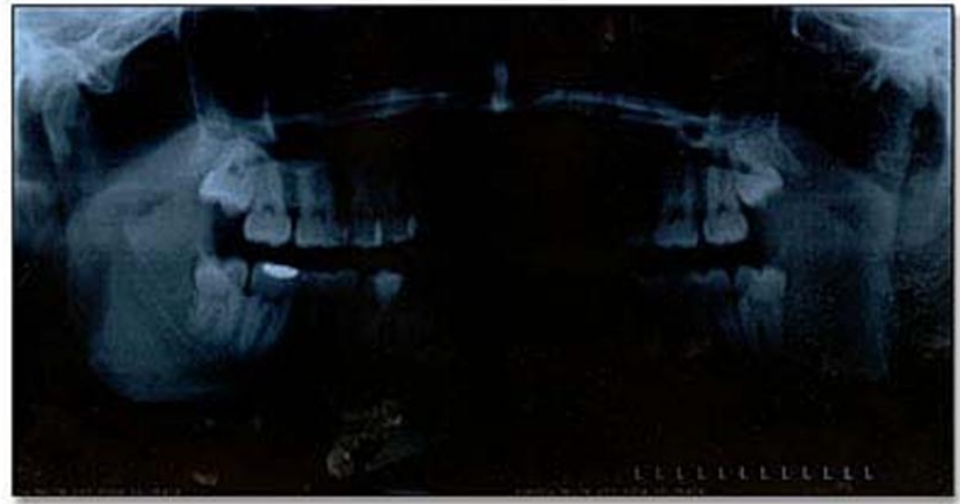

Figure 4. Film density too high.
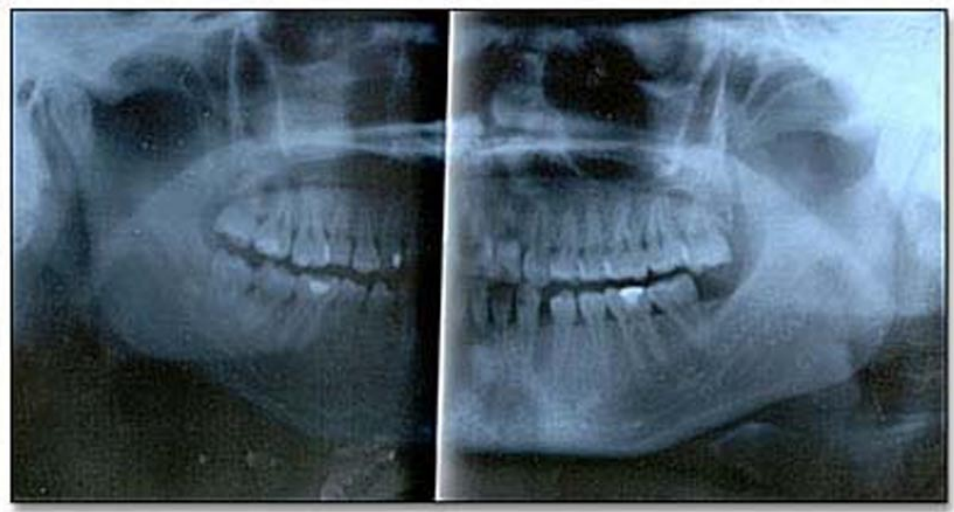

Figure 6 . Bent film 
Table 1. Frequency of errors at the evaluated panoramic radiographs. Some films had more than one error so the percentages add up to more than 100 percent.

\begin{tabular}{|l|l|l|}
\hline Error & $\mathbf{n}$ & $\%$ \\
\hline Shadow of airway above tongue & 213 & 46.30 \\
\hline Superimposition of hyoid bone & 121 & 26.30 \\
\hline Vertebral column superimposed on anterior teeth & 102 & 22.17 \\
\hline Density too high & 76 & 16.52 \\
\hline Density too low & 72 & 15.65 \\
\hline Occlusal plane tipped down & 62 & 13.47 \\
\hline Asymetrical placement of teeth & 53 & 11.52 \\
\hline Other miscellenous errors & 45 & 9.78 \\
\hline Occlusal plane tippd up & 43 & 9.34 \\
\hline Film fogged & 34 & 7.39 \\
\hline Blurring of anterior teeth & 32 & 6.95 \\
\hline Stains on film & 29 & 6.30 \\
\hline Superimposition of spine on other sturctures & 26 & 5.65 \\
\hline Narrowed anterior teeth & 26 & 5.65 \\
\hline Radiopaque artifact & 24 & 5.21 \\
\hline Patient movement & 15 & 3.26 \\
\hline Vertical overlap of anterior teeth & 2.39 \\
\hline Marks on film & 11 & 1.32 \\
\hline Widening of anterior teeth & 0.21 \\
\hline Films dirty or bent & & \\
\hline N= number & 7 & \\
\hline
\end{tabular}




\section{Discussion}

The focal trough of the panoramic X-ray unit is a three dimensional curved zone in which structures are reasonably well defined on the panoramic radiographs, and it is important for obtaining high quality images of the structures of interest. ${ }^{1}$ The limited dimension of the focal trough, carelessness of operator, and age of the machine affects the occurrence of some errors. The image seen on a panoramic radiograph consists largely of the anatomic structures located within the focal trough. Objects in front or behind it are blurred, magnified or reduced in size, and are sometimes distorted to the extent of being unrecognizable. ${ }^{1,2}$ (Figure 7) The limited dimensions of the

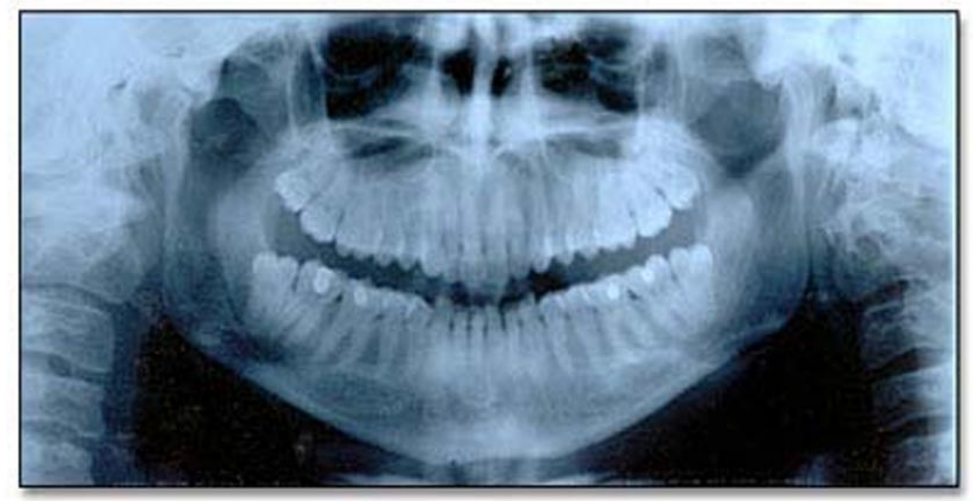

Figure 7. Narrowed anterior teeth, blurred image and occlusal plane is tipped upward.

focal trough makes minor errors in positioning to manifest as distortions due to unequal vertical and horizontal magnification, overlapping of teeth, and loss of image sharpness. ${ }^{4}$

Taking radiographs with older machines tends to increase error rates because with extended use the location of the focal trough could change necessitating recalibration if suboptimal images are consistently produced. ${ }^{11}$ In the present study, radiographs were taken with a 4 year old machine.

In our dental school, training in panoramic radiography is only given to radiology asistants and technicians, not to dental students. The radiographs in this study were taken with the panoramic radiographic technique by two trained dental assistants with 2.5 and 3 years of experience, respectively. The rate of error free films taken by trained radiology assistants was found to be $37.61 \%$. Schiff et al. ${ }^{8}$ reported that out of 1,000 evaluated radiographs taken with different machines, $20.3 \%$ were error free. The total percentage of errors on films taken by a trained technician was less than randomly selected films at a dental school which were taken either by technicians, dental students, dental auxilaries, or faculty members. On the other hand, Rushton et al. ${ }^{9}$ stated the error free rate of films as $0.8 \%$ in a sample of general dentisits. It seems logical that offering instruction in a relatively new and unfamiliar technique would enable operators to produce better radiographs. The results emphasize the importance of training in the use of panoramic radiographic equipment and the need of a quality assurance regimen including the correction of errors.

The OP100 uses a light positioning system consisting of three separate light beam indicators projected on the patient to align the Frankfurt horizontal plane and the midsagital vertical plane. In addition, it has an automatic exposure control unit which helps to eliminate most exposure problems. In this study, the films were exposed using the automatic exposure control system.

Radiographs were taken by only two trained radiology assistants with an OP100, which is a high quality machine ${ }^{1}$, so the rate of error free radiographs could seem to be better than the other studies.

On the other hand, under these standards of radiography interpretation, the error rates could seem to be high when the biological effects of ionizing radiaton is discussed.

The most common error was found to be the presence of airspace above the tongue. This results when the patient does not raise the tongue against the palate and holds it there until the exposure has been completed. Thus, the resulting air is seen on the radiograph as a radiolucent

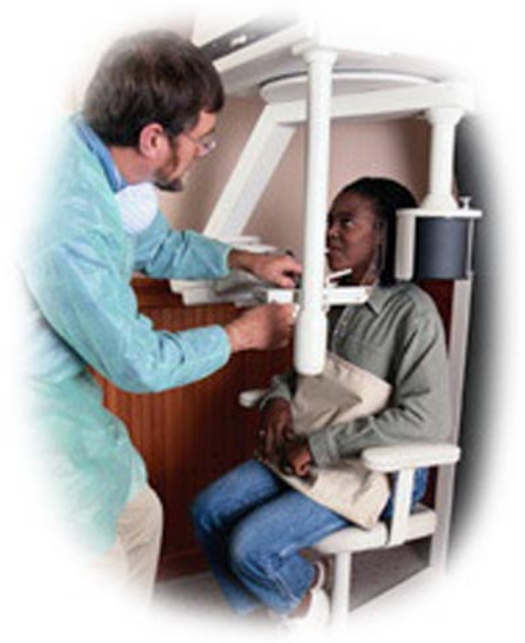


band over the roots of the maxillary teeth. This can reduce the diagnostic quality of the roots and its surrouding structures. Instructing a patient on proper tongue position does not guarantee compliance during the expsosure. In recent studies, ${ }^{6,8,9}$ this was also found to be the most common positioning error. From our experiences, patients sometimes find it difficult and get confused when asked to raise their tongue against the palate. This might suggest the reason for such a high rate of error.

High density was the most common technical error seen which led to the loss of diagnostic information on radiographs. This could be caused by overexposure or processing errors. While taking panoramic radiographs, the operator must pay careful attention to the exposure settings, intensifying screen, and its corresponding film and film processing. The manufacturers recomendations must be followed.

Only adult patient panoramic radiographs were included in this study. Pediatric patient radiographs were excluded from the study be- cause of technical faults like movement and positioning errors that might occur at a higher rate affecting the results. This could be assessd in another investigation.

Sometimes errors could occur beyond the operator's control in patients having facial asymmetry, a short and heavy neck, extremely overweight, unusually tall, and the inability of following instructions. ${ }^{8}$ These conditions make it difficult to position the patient properly in the $\mathrm{X}$-ray unit. The operator must be more careful in positioning these patients. Although errors beyond the operator's control may occur, most errors are within the control of the operator and could be eliminated by paying closer attention to the procedure.

\section{Conclusion}

From the results of the study, the percentage of error-free radiographs taken by trained radiology assistants was found to be $37.61 \%$. The most common error seen on the radiographs was the palatoglossal airspace. Training of dental personnel and a discussion of technical measures to be taken if errors occur are essential to maximize the quality of panoramic radiographs.

\section{References}

1. Panoramic radiography. In: White $S C$ and Pharoah $M \mathrm{~J}$. Oral radiology: principles and interpretation. St. Louis: C V. Mosby Inc.; 2000: 205-216.

2. Panoramic radiography. In: Frommer $\mathrm{H} \mathrm{H}$. Radiology for dental auxillaries. St. Louis $\mathrm{C}$ V. Mosby Inc;1992:200-214.

3. Radiographic projections and anatomical features. In: Brocklebank L. Dental radiology: Understanding the X-ray image. New-York: Oxford University Press; 199718-41.

4. Damante JH, Filho LI, Silva MA. Radiographic image of the hard palate and nasal fossa floor in panoramic radiography. Oral Surg Oral Med Oral Pathol Oral Radiol Endod. 1998 Apr;85(4):479-84.

5. Thorogood J, Horner K, Smith NJ. Quality control in the processing of dental radiographs. A practical guide to sensitometry. Br Dent J. 1988 May 7;164(9):282-7. No abstract available.

6. Rumberg $\mathrm{H}$, Hollender L, Oda $\mathrm{D}$. Assessing the quality of radiographs accompanying biopsy specimens. J Am Dent Assoc. 1996 Mar;127(3):363-8.

7. Brown RS, Coleman-Bennett MM, Jones-Matthews T. Synthetic hair braid extension artifacts in panoramic radiographs. J Am Dent Assoc. 1998 May;129(5):601-4.

8. Schiff T, D'Ambrosio J, Glass BJ, et. al. Common positioning and technical errors in panoramic radiography. J Am Dent Assoc. 1986 Sep;113(3):422-6. No abstract available.

9. Rushton VE, Horner K, Worthington HV. The quality of panoramic radiographs in a sample of general dental practices. Br Dent J. 1999 Jun 26;186(12):630-3.

10. Brezden NA, Brooks SL. Evaluation of panoramic dental radiographs taken in private practice. Oral Surg Oral Med Oral Pathol. 1987 May;63(5):617-21.

11. Razmus TF, Glass BJ, McDavid WD. Comparison of image layer location among panoramic machines of the same manufacturer. Oral Surg Oral Med Oral Pathol. 1989 Jan;67(1):102-8. 


\section{Zuhre Zafersoy Akarslan, BDS}

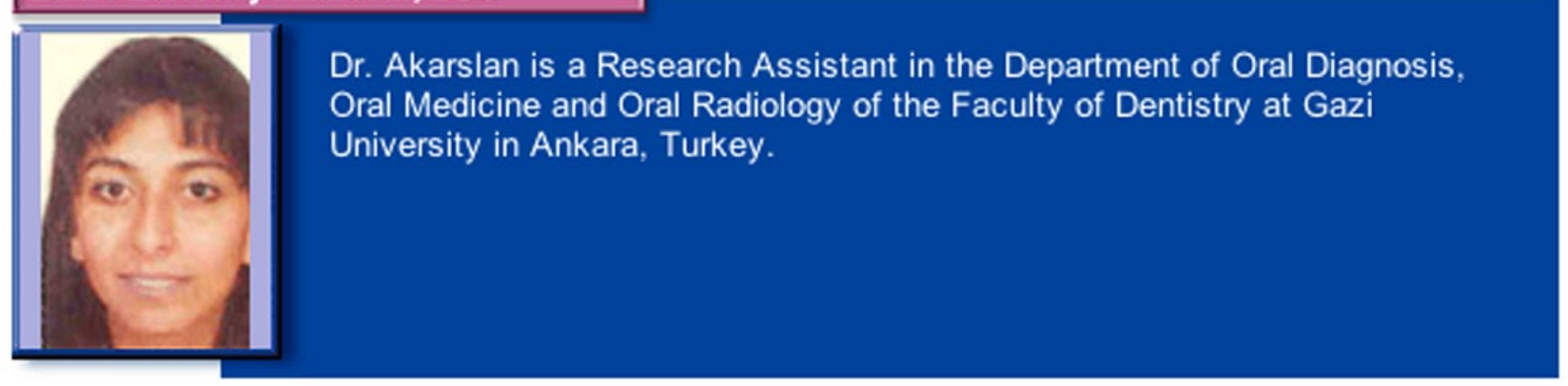

\section{Hülya Erten, BDS, PhD}

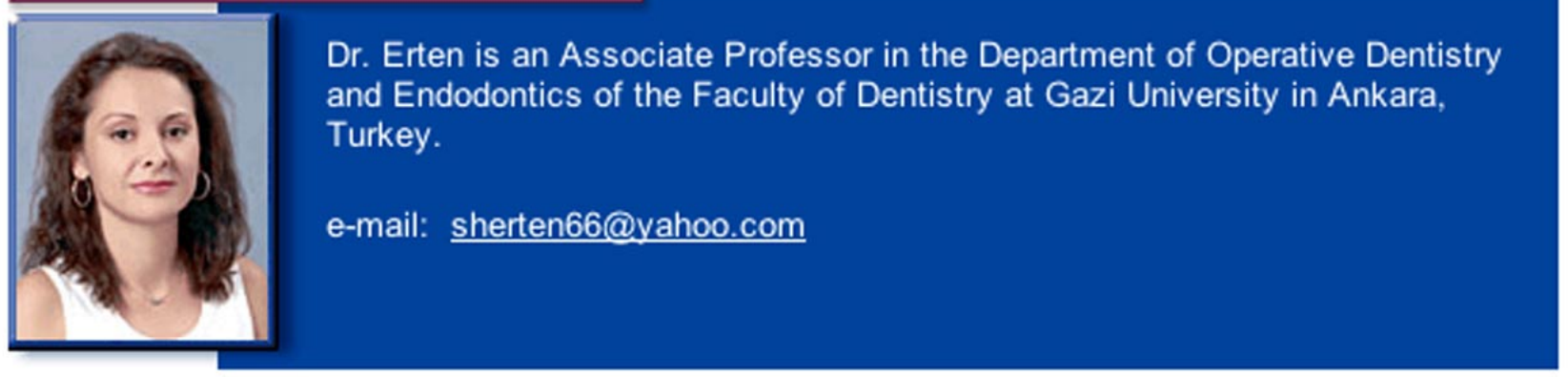

\section{Kahraman Güngör, BDS, PhD}

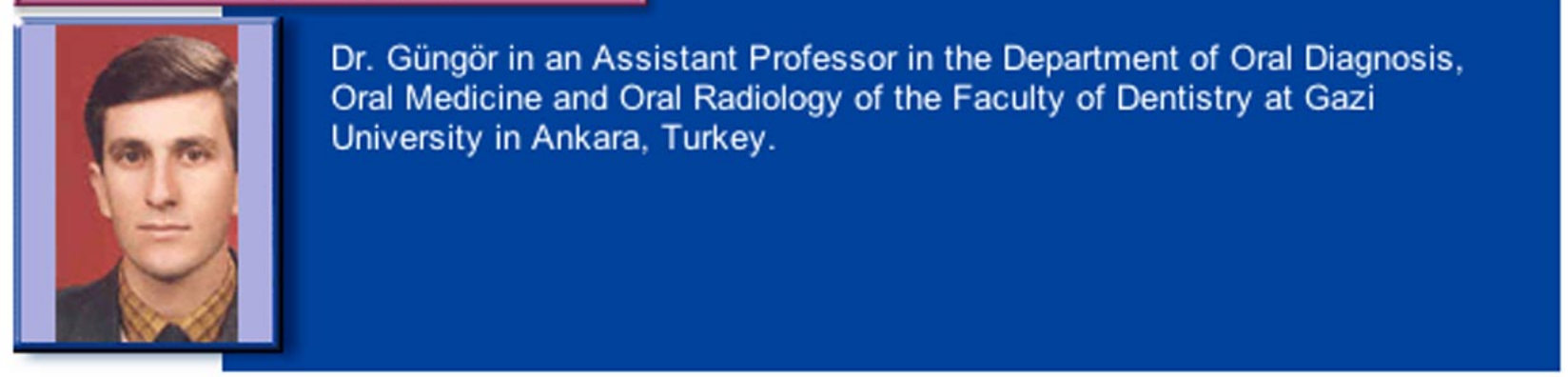

\section{IIkay Celik, BDS}

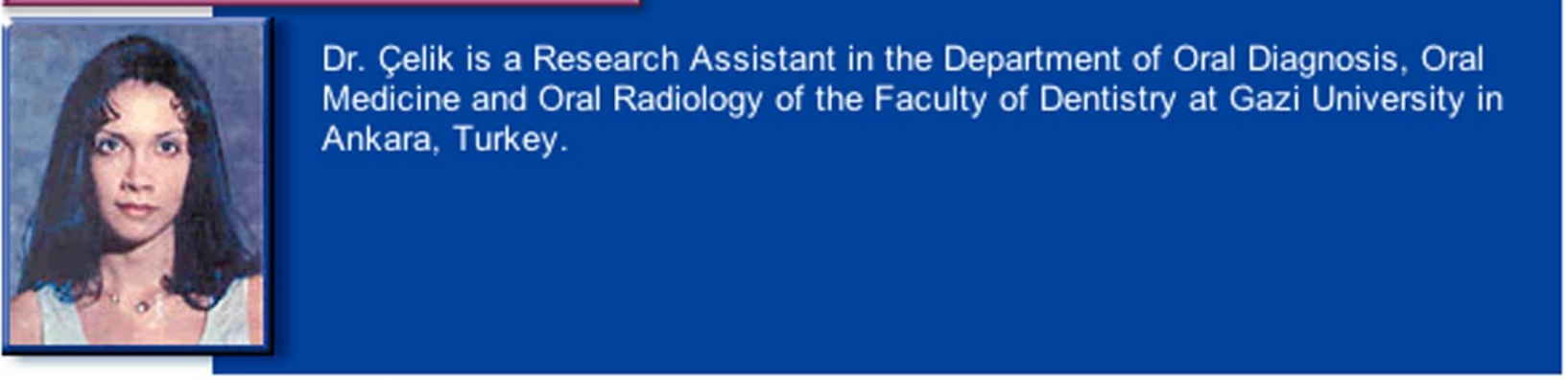

